\title{
Controversies in epidemiology of occupational asthma
}

\author{
D. Gautrin*, A.J. Newman-Taylor*, H. Nordman`, J-L. Malo*
}

Controversies in epidemiology of occupational asthma. D. Gautrin, A.J. NewmanTaylor, H. Nordman, J-L. Malo. C) ERS Journals Ltd 2003.

ABSTRACT: Epidemiology is the study of the distribution, determinants and outcome of disease. In this article, the recently acquired knowledge of the epidemiology of occupational asthma is described, as well as current areas of controversy.

Incidence figures obtained from field studies in high-risk workplaces, medicolegal statistics and sentinel programmes indicate that $\sim 10 \%$ of adult-onset asthma is attributable to the workplace. The strategy to identify cases through questionnaires and tools that address functional, immunological and physiopathological issues needs to be improved.

Although few in number and limited to a handful of workplaces, cohort studies found that the risk of developing occupational asthma is determined less by individual susceptibility (e.g. atopy, tobacco smoking, human leukocyte antigen phenotype) and more by the level of exposure to its causes; in general, the higher the exposure, the greater the risk, and, by implication, lowering the level of exposure reduces the incidence of disease.

Occupational asthma can be used as a satisfactory model for the development of adult-onset asthma. There is a great need to develop intervention strategies through adequate surveillance programmes in high-risk workplaces. Eur Respir J 2003; 22: 551-559.
*Dept of Chest Medicine, Hôpital du SacréCœur de Montréal, Montréal, Canada. ${ }^{\#}$ Dept of Occupational and Environmental Medicine, Imperial College School of Medicine, National Heart and Lung Institute, London, UK. "Dept of Occupational Medicine, Finnish Institute of Occupational Health, Helsinki, Finland.

Correspondence: D. Gautrin, Dept of Chest Medicine, Hôpital du Sacré-Cœur de Montréal, 5400 Boul, Gouin Ouest, Montréal H4J 1C5 Canada.

Fax: 15143383123

E-mail: d-gautrind@crhsc.umontreal.ca

Keywords: Asthma epidemiological designs occupational lung diseases

Received: April 302003

Accepted after revision: May 122003

\section{Epidemiology of occupational asthma: general considerations on various study designs and methodological approaches}

Epidemiology is the study of the distribution, determinants and outcome of disease. In this article, the authors will describe recently acquired knowledge of the epidemiology of occupational asthma, as well as current areas of controversy.

BECKLAKE et al. [1] have discussed the features, strengths and weaknesses of several designs used in epidemiological studies. These designs include the randomised control trial, the prospective cohort, the case-referent study, the crosssectional (prevalence) study and the case series. Which design to use in any particular situation is a matter of judgment, determined by a number of factors that may include resources, cost, collaboration of employers and employees, and the question under study. So far, primarily for practical convenience, most epidemiological studies of occupational asthma have been cross-sectional in type. As discussed in several reviews [1,2], this type of study, primarily in the case of occupational asthma (OA), suffers from survivor bias, whose magnitude can be difficult to quantify. Randomised control trials are usually not feasible and are probably unethical in workplace studies, but quasi-experimental studies can provide results of high internal and external validity. Prospective cohort studies are more expensive than cross-sectional studies but are more powerful and less likely to be affected by selection or survivor biases; in particular, it is often possible to track the participants who leave the cohort and determine the possible effect of attrition on the estimates of both the frequency of $\mathrm{OA}$ and exposure/effect relationships [3]. This type of study has recently been successfully applied in cohorts of young apprentices [4-10]. Some case-referent studies have been carried out in the field of OA [11, 12]. These studies are valuable in identifying and quantifying risk factors. Finally, there are many case series that mainly describe clinical cases (often single cases) caused by agents not previously incriminated. These series are valuable in describing, in depth, the clinical, functional and physiopathological aspects of OA and in informing clinicians about the potential work-relatedness of asthma in those exposed to these causal agents. Useful data taken from relevant and valuable series are published on websites [13, 14].

The means to investigate OA "in the field" should be improved. Although there is a well-validated epidemiological questionnaire for investigating asthma [15], there is no validated tool for OA. As suggested by TOELLE et al. [16], ascertaining cases of asthma or of OA should be based on questionnaire and confirmed bronchial hyperresponsiveness to pharmacological agents that are safe for field studies [17]. Several studies have incorporated skin-prick testing to assess immunoglobulin (Ig)E-based immunological sensitisation,

Previous articles in this series: No. 1: Vandenplas O, Malo J-L. Definitions and types of work-related asthma: a nosological approach. Eur Respir J 2003; 21: 706-712. No. 2: Moscato G, Malo J-L, Bernstein D. Diagnosing occupational asthma: how, how much, how far? Eur Respir J 2003; 21 : 879-885. No. 3: Mapp CE. The role of genetic factors in occupational asthma. Eur Respir J 2003; 22: 173-178. No. 4: Sastre J, Vandenplas O, Park H-S. Pathogenesis of occupational asthma. Eur Respir J 2003; 22: 364-373. 
reflecting the interest of immunologists and allergists, or bronchial responsiveness testing, reflecting the interest of pneumologists, but very few have used both tools. A combination of the presence of IgE-mediated sensitisation and bronchial hyperresponsiveness makes a diagnosis of OA highly likely [18]. It might also prove valuable to go to a step further in subsamples, e.g. by using serial peak expiratory flow (PEF) measurements with automated interpretation of graphs (OASYS) [19].

\section{Prevalence of occupational asthma}

Towards the end of the 20th century, just as other workrelated respiratory illnesses, such as pneumoconiosis, were on the decline in industrialised countries, the prevalence and incidence of OA began to increase $[1,20]$. This may have been due, at least in part, to changing environmental conditions in the workplace, i.e. the introduction of new asthmagenic agents. It is interesting to note that at the time this increase was observed, the prevalence and incidence of asthma in the general population had also increased; in the USA, for example, it increased between 1982 and 1994 from 40 in 1,000 to 60 in 1,000 [21]. This increase may have contributed to the increasing rates of $\mathrm{OA}$ among work-related lung diseases in Westernised societies [1].

The prevalence of sensitisation to inducers of OA, specifically $\mathrm{IgE}$ and/or $\operatorname{IgG}$, and work-related respiratory symptoms suggestive of $\mathrm{OA}$ have been investigated in several different workplace surveys and among workers in the same occupational groups, e.g. in laboratory animal facilities, large bakeries, snow crab and other seafood processing, food processing, farming, silk work, latex glove manufacturing, carpet manufacturing, pharmaceutical industry, plastic and varnish production and/or utilisation, spray-painting, hairdressing, production of resins, sawmill, welding, textile (dyes), hospitals etc. [22], and greenhouses [23]. These surveys have been restricted to individual workplaces or to groups of individuals from the same occupation [24]. More recently, population-based studies have been undertaken to estimate the prevalence of OA [25-27]; in addition, data from population surveys have been analysed to derive such estimates [28]. These results are helpful in providing information about the size of the problem in high-risk workplaces, although they are potentially prone to survivor bias. The well-known survivorbias effect (selection "out," which is to be distinguished from selection "in" or the "healthy-worker effect") is probably the most important bias affecting prevalence estimates from cross-sectional surveys, particularly in individual workplaces; indeed, particular conditions at a given site, such as exposure to other asthmagenic agents or respiratory irritants, may account, at least in part, for reported differences in the prevalence of OA due to the same agent.

Large discrepancies in the prevalence of sensitisation, work-related symptoms and OA between workforces exposed to different agents (e.g. isocyanates, flour, laboratory animals) have been reported. One may question whether these are entirely attributable to the agents themselves or to other circumstances, e.g. country, differential effect of other factors, such as work practice, and potential identified/nonidentified biases? Attempts to reduce the effect of these potential confounders by selection of appropriate working groups (e.g. different industries from the same country) for prevalence surveys and comparisons could help resolve this.

Information bias can result from using different methods to collect the data, such as symptom questionnaires or objective tests, such as skin-prick and non-specific bronchial challenge tests.
The definition of OA in epidemiological studies can vary according to the study question, study design and study population; this fact is well accepted among asthma epidemiologists [1]. However, when comparisons are made between prevalence surveys, the definition of OA becomes an important issue; different definitions can obviously lead to substantial ascertainment bias. OA has been defined as: 1) the presence of respiratory symptoms at work (e.g. symptoms of wheezing, cough, dyspnoea, chest tightness that resolve after some time away from work $[18,29,30]$; or 2 ) as one or the other of combinations that include work-related respiratory symptoms, specific immunological sensitisation [31], variation in serial peak-flow measurements [32-34] and increased nonspecific bronchial responsiveness [7]. As uncertainty persists in the ascertainment of OA in epidemiological studies, the terms "asthma-like," "possible OA" [25] and "probable OA" [7, 25] have been used to describe the syndrome. An additional source of controversy in the ascertainment of OA is that it can be defined as new-onset asthma [22] or as workaggravated asthma [35].

Prevalence estimates are likely to vary according to the basis of the definition adopted; questionnaire-derived identification of OA provides higher estimates of OA because of the high sensitivity of the instrument, but its poor specificity produces a large proportion of false positives [36]. A stepwise approach has been suggested with further investigation of subjects reporting symptoms suggestive of OA [37-40]. Selecting a subset of respondents at random from a population sample has been an alternative method for obtaining extended information by detailed questionnaires, skin-prick tests, measurements of specific IgE, spirometry and methacholine challenge [41]. A remarkable effort was made in the European Community Respiratory Health Survey. For the first time, the same investigation methods and definitions were used to assess the variation in the prevalence of asthma in 22 countries with $\sim 140,000$ participants $[39,41]$ and to determine the risk of asthma attributable to occupational exposures using data sets from Spain [26], New Zealand [42], Sweden [43] or the whole data set [27].

Some prevalence surveys have provided information about exposure/response relationships, however, over time, the healthy-worker effect, survivor bias and changes in exposure levels are likely to attenuate exposure/response relationships.

Prevalence surveys will remain useful for the study of workforces exposed to a newly recognised agent and in countries where OA and the circumstances in which it occurs are not well recognised. It will be important in the future to ensure uniformity of the methods used to assess the prevalence of OA (i.e. uniform criteria to define OA, same diagnostic tools to allow comparison of the results from different studies).

\section{Estimates of the incidence of occupational asthma}

The incidence of OA has been explored in at least three different types of study.

\section{Incidence studies in high-risk workforces}

A limited number of prospective studies have been carried out in workers exposed to agents known to cause OA. These include the study of workers exposed to detergent enzymes in the late 1960's and early 1970's [44] and cohort studies of workers exposed to laboratory animals [13] and flour [14]. These studies have been valuable in identifying the risk factors (including exposure) associated with sensitisation to high-molecular weight agents and work-related symptoms. 
Table 1.-Advantages of proposing the model of prospective cohort studies in apprentices in the investigation of the natural history of occupational asthma

\begin{tabular}{|c|c|}
\hline Characteristics & Advantages \\
\hline \multirow[t]{3}{*}{$\begin{array}{l}\text { Related to } \\
\text { the subjects }\end{array}$} & $\begin{array}{l}\text { No previous effect of exposure to the causal } \\
\text { agent }\end{array}$ \\
\hline & Minimal effect of smoking \\
\hline & $\begin{array}{l}\text { Possibility of having a well-balanced sample } \\
\text { of atopic and nonatopic individuals, as } \\
\text { well as a sufficient number of subjects } \\
\text { with enhanced bronchial responsiveness } \\
\text { representative of the fraction of the general } \\
\text { population entering their professional life }\end{array}$ \\
\hline \multirow[t]{5}{*}{$\begin{array}{l}\text { Related to } \\
\text { the design }\end{array}$} & $\begin{array}{l}\text { Entirely prospective: characterisation of the } \\
\text { natural history of immunological } \\
\text { sensitisation and disease }\end{array}$ \\
\hline & $\begin{array}{l}\text { Best characterisation of important } \\
\text { co-morbidity factors on entry into the } \\
\text { cohort: atopy, level of bronchial } \\
\text { responsiveness, rhinoconjunctivitis }\end{array}$ \\
\hline & Repeated assessment possible \\
\hline & Serial identification of level exposure \\
\hline & $\begin{array}{l}\text { Possibility of follow-up at the time subjects } \\
\text { enter a workplace and serially thereafter, } \\
\text { including after removal from exposure } \\
\text { in cases where subjects develop disease }\end{array}$ \\
\hline
\end{tabular}

Prospective cohort studies in apprentices who start a career in a high-risk occupation can provide advantages, as summarised in table 1. Two groups have used this model.

In a prospective study of 125 trainee bakers studied 6,18 and 30 months after an initial assessment, DE ZOTTI and BOVENZI [5] found a cumulative incidence of skin sensitisation to wheat flour or $\alpha$-amylase of $10.1 \%$ and of work-related respiratory symptoms of $9.0 \%$ [5]. A personal history of allergic diseases and skin sensitisation to a work-related allergen were significantly associated with the onset of workrelated chest symptoms. GAUTRIN and co-workers $[4,6,7,10]$ and ARCHAMBAULT et al. [9] are currently examining cohorts of nearly 770 trainees exposed to high-molecular weight agents and nearly 650 trainees exposed to low-molecularweight agents (welding fumes and isocyanates).

A summary of results obtained in 769 trainees in animal health technology, pastry making and dental hygiene exposed to high-molecular weight allergens has also been published [45]. The major findings were as follows. 1) On entry into the apprenticeship, a significant proportion of apprentices showed signs of immunological sensitisation. In addition, there was apparently no self-selection, due to prior sensitisation to the relevant allergens (table 2) [4]. 2) Of the 89 out of $769(11.6 \%)$ students who quit their training programme, a history of hay fever on entry into the apprenticeship (odds ratio (OR) 1.66, 95\% confidence interval (CI) $1.0-2.75$ ) and attending the pastry-making programme (OR 2.33, 95\% CI

Table 2.-Skin sensitisation to work-related allergens on entry into an apprenticeship programme

\begin{tabular}{lccc}
\hline & $\begin{array}{c}\text { Animal } \\
\text { health }\end{array}$ & $\begin{array}{c}\text { Pastry } \\
\text { making }\end{array}$ & $\begin{array}{c}\text { Dental } \\
\text { hygiene }\end{array}$ \\
\hline Subjects & 414 & 222 & 122 \\
Atopy & $225(54.4)$ & $129(58.1)$ & $64(52.5)$ \\
Urinary proteins & $28(6.8)$ & $15(6.8)$ & $9(7.4)$ \\
Flour & $5(1.2)$ & $11(5.0)$ & $5(4.1)$ \\
Latex & $3(0.7)$ & $1(0.5)$ & $1(0.8)$ \\
\hline
\end{tabular}

Data are presented as $\mathrm{n}(\%)$.
Table 3. - Incidence of programme-related sensitisation

\begin{tabular}{lccc}
\hline & $\begin{array}{c}\text { Animal } \\
\text { health }\end{array}$ & $\begin{array}{c}\text { Pastry } \\
\text { making }\end{array}$ & $\begin{array}{c}\text { Dental } \\
\text { hygiene }\end{array}$ \\
\hline Subjects n & 395 & 186 & 109 \\
Incident cases n & 85 & 8 & 7 \\
Proportion by number at risk \% & 21.5 & 4.3 & 6.4 \\
Rate by person-year \% & 7.9 & 4.2 & 2.5 \\
\hline
\end{tabular}

1.11-4.91) were significantly associated with quitting [3]. 3) The risk of sensitisation during the training programme was higher for apprentices exposed to animal-derived allergens than for those exposed to flour and latex. There was no excess of sensitisation to flour in bakers, compared with the other groups not exposed to this allergen at work (table 3) [6]. 4) In apprentice animal technicians exposed to laboratory animals, atopy (rate ratio (RR) $2.20,95 \%$ CI 1.4-3.91), respiratory symptoms in the pollen season (RR 5.19, 95\% CI 1.68-16.05) and spending $>52 \mathrm{~h}$ exposed to rodents (RR 2.51, 95\% CI $1.32-4.76)$ were significantly associated with incident-specific sensitisation to a laboratory animal-derived allergen adjusting for possible confounders [6]. Determinants for the development of specific sensitisation, symptoms and disease are different in atopic and nonatopic subjects [46]. The rate of sensitisation was higher in the first 2 yrs (out of a total of $4 \mathrm{yrs}$ ) of training (10.3 and $10.7 \%$ for years 1 and 2 , respectively), as was work-related rhinoconjunctivitis (12.5 and $13.9 \%$ for years 1 and 2, respectively), whereas respiratory symptoms took longer to appear (maximum incidences of 3.2 and $2.5 \%$ in years 2 and 3 of the programme, respectively) [8]. The incidence of probable OA was $2.7 \%$ ( 28 out of 1,043 person-yrs). Baseline immediate skin reactivity to pets (RR 4.1, 95\% CI 1.6-10.8) and bronchial responsiveness (provocation concentration causing a $20 \%$ fall in forced expiratory volume in one second (FEV1) (PC20) $\leqslant 32$ versus $\left.\mathrm{PC} 20>32 \mathrm{mg} \cdot \mathrm{mL}^{-1}\right)(\mathrm{RR} 2.5,95 \%$ CI $1.0-5.8)$ were significant risk factors for probable OA. A higher FEV1 was mildly yet significantly associated with an increase risk of probable OA (RR 1.74, 95\% CI 1.29-2.34) [7]. 5) In apprentices exposed to latex, the cumulative incidence for skin sensitisation, probable occupational rhinoconjunctivitis and OA to latex were $6.4,1.8$ and $4.5 \%$, respectively. Subjects sensitised to latex were more likely to be atopic and to have a previous history of asthma and respiratory symptoms on exercise than nonsensitised subjects [9]. 6) In apprentice pastry makers, work-related rhinoconjunctivitis symptoms were common (16.1\% of subjects; 13.1 per 100 person-yrs), but concomitant occurrence with skin sensitisation to flour was rare (3 out of $186,1.6 \%)$ [10].

In another study looking at the incidence of self-reported (physician-diagnosed) asthma in high-risk groups, BRISMAN and JÄRVHOLM [47] used an interesting study design. They applied a retrospective cohort design among persons trained as bakers in 1959-1989 $(n=2,923)$ and two different referent groups, one comprising persons who followed another programme in the trade school and another randomly selected from the population register. First, the RR for bakers was 1.8 (95\% CI 1.3-1.6), whereas there was no difference in the prevalences. Secondly, they also studied nonrespondents, which really should always be done, and found that the bakers had changed work significantly more often than controls.

\section{Medical, medicolegal and compensation statistics}

Medical practice can be informative. It was recently reported that some $5 \%$ of all cases of asthma referred to a 
tertiary-care hospital were likely to be of occupational origin [48]. Medicolegal statistics can also be useful and devoid of significant ascertainment and selection biases, provided that the diagnosis is sufficiently convincing, that all types of occupations are covered and that workers request an examination of their condition. Compensation for OA and medicolegal handling of accepted cases are unsatisfactory in many countries, including developed countries such as the UK [49] and France [50], because workers may not apply for compensation. Many agencies that examine claims for OA use data that are insufficiently reliable (history alone, skin-prick tests alone, etc.) [51] to make a confident diagnosis [52]. OA is more satisfactorily compensated in Finland and Quebec and the diagnosis is based on specific inhalation challenges and/or PEF monitoring. Approximately 50-70 cases have been accepted in Quebec since 1990, which implies incidence rates of two cases per 100,000 employed [53]. The Finnish Register of Occupational Diseases (FROD) is a register based on mandatory reporting by physicians [54]. It was established in 1964 and is maintained by the Finnish Institute of Occupational Health. Since 1974, physicians have been obliged by law to report known or suspected occupational diseases to the provincial labour protection authorities. There is a reasonably good coverage of the population, particularly since 1982, when farmers became eligible for compensation. Insurance, which is compulsory for all employed workers, is voluntary for the self-employed, roughly half of whom have an insurance policy [55]. More than $90 \%$ of the cases are ascertained by serial peak-flow measurements and/or specific inhalation tests [54]. The high incidence of OA (17.4 cases per 100,000 employed) is, to a large extent, accounted for by the high incidence among farmers (1,400 per million, 95\% CI 1,204 1,621) [55].

The Swedish figures are based on self-reporting. Employees complete a form that provides information about diagnosis, causes and current workplace. The employer countersigns the report. All claims are listed in the Swedish Register of Reported Occupational Diseases (SRROD). Information on successful claims does not appear in the register [56]. Contrary to what might be expected, the self-reported incidence of OA in Sweden is lower than that found in Finland. The incidence was high in some occupations not formerly associated with any risk of OA, such as furnace work, foundry and steel-mill work, welding (other than stainless-steel welding), logging and cooking.

\section{Sentinel programmes}

Voluntary reporting schemes of cases of OA are another means of estimating the incidence of the condition. In the UK, two voluntary reporting schemes have proved effective since 1989. The Surveillance of Work-Related and Occupational Respiratory Disease (SWORD) draws on reports of newly diagnosed occupational lung disease from specialists in occupational or respiratory medicine in the UK. The other voluntary scheme, Midland Thoracic Society's Rare Respiratory Disease Registry Surveillance Scheme of Occupational Asthma (SHIELD), covers only the West Midlands (reports received from the specialists reporting to both schemes inevitably overlap) $[57,58]$. Results of the 1989-1997 period for SWORD have recently been published [57]. The most recent figures show stabilisation in the number of new cases with limited variation in the number of cases due to specific agents. Sentinel programmes have also been carried out elsewhere in the world. In South Africa, for example, a voluntary programme resembling the SWORD was launched in 1996 to monitor occupational respiratory disease [59]. OA was the second most common reported disease with an overall incidence of 13 per million in 1996-1998. There was an incidence range of $0-36$ per million per year between the nine participating provinces. Differences seemed likely to reflect access to health services, with $94 \%$ of all reports accounted for by three provinces.

In the USA, the Sentinel Event Notification System for Occupational Risks (SENSOR), has been operating in six states since 1988. The objectives of SENSOR are to identify potentially dangerous sentinel cases in the work environment and to subsequently initiate investigations and implement interventions. Cases reported must be diagnosed by a physician [60, 61]. The aim of SENSOR is not to measure disease frequency; the incidence figure is therefore not comparable to the other reporting schemes. Similar sentinel programmes have been run elsewhere [62].

\section{Figures from and comments on medicolegal statistics and sentinel-based programmes}

Table 4 represents some incidence studies from five different countries. Some of them cover regions, others whole countries. The annual overall incidence rates per million

Table 4. - Incidence of work-related asthma according to sentinel-based and medicolegal data

\begin{tabular}{|c|c|c|c|c|c|}
\hline $\begin{array}{l}\text { Country } \\
\text { Author [ref.] }\end{array}$ & Region/source & Years & $\begin{array}{l}\text { Number } \\
\text { of cases }\end{array}$ & $\begin{array}{c}\text { Annual rate per } \\
10^{6} \text { per year }\end{array}$ & $95 \% \mathrm{CI}$ \\
\hline \multicolumn{6}{|l|}{ Canada } \\
\hline LAGIER et al. [53] & Quebec, Canada & $1986-1988$ & 214 & 25 & $22-29$ \\
\hline CONTRERAS et al. [62] & British Columbia, Canada & 1991 & 124 & 92 & \\
\hline \multicolumn{6}{|l|}{ Finland } \\
\hline KARJALAINEN et al. [54] & All/FROD & $1990-1995$ & 2281 & 175 & $168-182$ \\
\hline \multicolumn{6}{|l|}{ Sweden } \\
\hline TORÉN et al. [56] & All/SRROD & 1990-1992 & 1010 & 80 & $70-90$ \\
\hline \multicolumn{6}{|l|}{ UK } \\
\hline MEREDITH and NORDMAN [55] & All/SWORD & $1992-1993$ & 954 & 37 & $35-39$ \\
\hline GANNON and BURGE [58] & West Midlands/SHIELD & $1889-1991$ & 284 & 43 & $38-48$ \\
\hline \multicolumn{6}{|l|}{ USA } \\
\hline MATTE et al. [60] & Michigan & 1988-1992 & 381 & 18 & $17-20$ \\
\hline JAJOSKY et al. [61] & Michigan & & & 29 & \\
\hline
\end{tabular}

95\% CI: 95\% confidence interval; all: whole country; FROD: Finnish Register of Occupational Diseases; SRROD: Swedish Register of Reported Occupational Diseases; SWORD: Surveillance of Work-Related and Occupational Respiratory Disease; SHIELD: Midland Thoracic Society's Rare Respiratory Disease Registry Surveillance Scheme of Occupational Asthma. 
workers range 16-175. The studies come from different sources, which partly accounts for the differences in reported incidences.

Estimated incidence figures based on voluntary or mandatory reporting programmes or disease registers have provided valuable information. Much of what is known about the distribution of disease by occupational categories and the frequency of disease by agent is derived from these reports. They are strongly dependent on the definition of OA, on job classifications, on how well motivated the physicians who report the disease are and on their skill at suspecting and recognising an association between adult-onset asthma and work exposures. The precision of the reported data, therefore, remains questionable. Indeed, there are conflicting influences on the magnitude of under- and over-reporting of cases. A physician may tend to suspect a diagnosis of OA in a subject with adult-onset asthma who is exposed to isocyanates, a well-known sensitising agent. Based on the experience of one of the authors (J-L. Malo), only one-third to one-fourth of all subjects with a clinical history suggestive of OA, not referred for medicolegal purposes and in whom specific inhalation challenges with occupational agents are performed develop an asthmatic reaction and therefore represent real cases of OA.

\section{Asthma attributable to work exposures}

During recent years, interest has turned to the fraction of adult-onset asthma that can be attributed to work exposures. In a review of available population studies, BLANC and TORÉN [63] arrived at a median overall estimate of the attributable risk of asthma to workplace exposure of $9 \%$ (range 5-25\%). Selected high quality studies yielded a somewhat higher median estimate of $15 \%$. Assessing excess risk of asthma to those in work environments associated with exposures as compared with workers in unexposed work environments is a way of estimating the fraction of asthma attributable to work. XU and CHRISTIANI [64] also arrived at an attributable fraction of $15 \%$ when studying physiciandiagnosed asthma in a community-based random sample of Beijing residents. This study registered excess asthma in workers exposed to dusts, gas, chemical fumes (i.e. irritants) and organic solvents.

Population-based incidence studies have not been commonly reported to date. MiLton et al. [65] reported the outcome of a cohort of 79,204 health maintenance organisation members in Massachusetts aged 15-55 yrs. Cases of newonset asthma and of recurrence of previous asthma were identified during the study period of 3 months. Criteria for onset of clinically significant asthma attributable to work exposures were met by $21 \%$ (95\% CI 12-32) (14 out of 66$)$ of new-onset and recurrent cases. The estimated annual incidence of asthma attributable to work was 400 per million (95\% CI 200-730) using only cases with "strong" evidence of occupational aetiology and 710 per million (95\% CI 4301110) when including those with "moderate" evidence.

A recent study included the entire employed Finnish population aged 25-59 yrs. The cohort was followed for 10 yrs [66]. The study was made possible by two registers: one of clinically established, persistent asthma; the other of census data. Census data from 1985, 1990 and 1995 were classified according to occupation. Relative risks were estimated for workers in any occupational category (exposed) in comparison with workers employed in administrative work (nonexposed). A total of 49,575 incident cases of asthma were recorded. The fraction attributable to occupation was $29 \%$ (95\% CI 25-30) for males and 17\% (95\% CI 15-19) for females. By comparison, a conservative estimate of asthma attributable to work using the FROD has been reported as $\sim 5 \%[67]$.

In a subsequent analysis of the same study population [68], all known cases of OA were removed. The relative risk of asthma remained significantly high in typically high-risk occupations, such as farming 1.76 (95\% CI 1.64-1.89), painting 1.77 (95\% CI 1.56-2.01) and baking 2.13 (95\% CI 1.74-2.83). These results suggest shortcomings in case ascertainment, even in high-risk occupations. This may be due to a failure to recognise association with work exposure, the failure of physicians to submit workers for examinations or too stringent diagnostic criteria. This study also found an excess risk in various work environments associated with exposure to irritants such as dusts, welding and soldering fumes, disinfectants, traffic or other exhaust combustion, and cold air.

Incidence estimates derived from reporting programmes, surveillance schemes and disease registers are usually lower than those obtained from population studies. This conspicuous difference has raised several important questions $[28,65$, $66,69]$. A possible explanation for the higher estimates of risk of asthma attributable to work exposure based on data derived from community-based studies is that such studies are more likely to include all individuals ever exposed in at-risk workplaces, rather than those currently exposed, thus reducing survivor effects. At present, asthma following irritant exposures, with the exception of acute irritant-induced asthma, is usually labelled as nonoccupational asthma. There is insufficient evidence about causation of asthma from long-term "low-dose" exposure to irritants. Several recent studies have found an increased risk of asthma in jobs associated with irritant exposures, in particular among construction and textile workers [70], cleaners [27, 54], shoemakers, metalplating workers and electrical machinery workers [28]. An increased risk of asthma in professions not normally associated with $\mathrm{OA}$ has led to the suspicion that proteins derived from ubiquitous agents may be responsible. Moulds in water-damaged buildings have been suggested as an explanation for an increased risk of asthma among educators [71], confirming two other recent reports [72, 73].

\section{Understanding of exposure/response relationships through cohort studies}

A few cohort studies have been published investigating the incidence of sensitisation and asthma caused by agents such as laboratory animals $[6,9,74]$, flour and $\alpha$-amylase [5, 10, 12], acid anhydrides [75], and latex [9, 76]. The duration of exposure has been used as a surrogate for direct assessment of allergen exposure, as the number of hours spent with laboratory animals was shown to be related to the incidence of IgE-mediated sensitisation to allergens derived from laboratory animals in an exposure/response manner. Atopy and pre-exposure respiratory symptoms during the pollen season were the other factors found to affect the incidence of specific sensitisation in a cohort of apprentices [6].

During the past decade, a number of studies have also included direct measures of exposure to the responsible agent (allergen or hapten) in the investigation of exposure/response relationships. Two prospective cohort studies, one of laboratory-animal workers [11], the other of flour mill and bakery workers [12], as well as a historical cohort of acid anhydride workers [75], were recently reviewed [49]. Briefly, among the animal workers, the risk of developing new work-related chest, eye/nose or skin symptoms was five-times greater in the highest, compared with the lowest, of four exposure categories; the increased risk for new work-related symptoms and skin-prick test responses to rat urinary proteins from working 
in the two highest exposure categories was two-or-more times greater than the increased risk of being atopic [11]. In the 5-yr cohort of workers exposed to flour and $\alpha$-amylase, the incidence was 7.7-times greater in workers exposed in the highest exposure category (category 3) compared with the lowest category, while atopic subjects were at no greater risk of developing chest symptoms than nonatopics [12]. A third cohort study performed in the UK among acid anhydride workers demonstrated an exposure/response relationship between increased exposure to trimellitic anhydride (TMA) and increased risk of developing a skin-prick test response to TMA and new work-related chest symptoms; the relationships were not modified by atopy or smoking [75]. All of these studies showed that the single strongest influence on the incidence of disease is exposure to the responsible agent; other factors, such as atopy and smoking are less important, as well as being less remediable.

These studies, in addition to another that adopted a casecontrol design where data of exposure measurements were obtained in a longitudinal manner in a factory using polyurethane products [77], have uniformly shown clear evidence of an exposure/response relationship for a number of different agents. Although other agents that cause OA have not been studied to the same extent, there is no evidence to suggest that they are not subject to similar exposure/response relationships. Studies such as these are costly and time consuming, but they provide evidence of sufficient strength to enable the development of preventive strategies for the most significant causes of OA, including flour, for which acceptable limits of exposure to prevent sensitisation and disease have been proposed [78]. Similar thresholds need to be proposed for other occupational agents [79].

\section{Occupational asthma as a satisfactory model for the study of adult-onset asthma}

The natural history of OA can be applied to the study of the natural history of asthma in an epidemiological model, as discussed elsewhere [80, 81], particularly if the model is applied to apprentices in high-risk workplaces (see above). Indeed, in such circumstances, it should be possible to obtain critical information that is relevant not only to OA but also to asthma, such as: 1) the role of predisposing factors before starting exposure (e.g. atopy, level of bronchial responsiveness, genetic factors); 2) determinants for the onset of sensitisation, airway inflammation and hyperresponsiveness, as well as of rhinoconjunctivitis and OA (this includes personal markers and environmental factors); and 3) factors that influence persistence and modulation of sensitisation and asthma after removal from exposure. Not only do prospective studies of OA provide information relevant to the natural history of asthma, but a prospective cohort study of young adults can also be designed to collect and provide useful information on: 1) the natural history of rhinoconjunctivitis, immunological sensitisation, bronchial responsiveness and asthma symptoms; and 2) how sensitisation and symptoms on exposure to occupational allergens can influence sensitisation and symptoms on exposure to common allergens [82].

\section{What still needs to be learnt}

It has become clear from the results of recent studies and systematic reviews that the proportion of new or recurrent asthma in adult life attributable to occupation is high, $\sim 10-15 \%$. Surveillance schemes, such as SWORD in the UK, as well as compensation statistics and epidemiological surveys of high-risk workforces, have identified the major causes of $\mathrm{OA}$ and the occupations in which cases occur. Strikingly, during the decade since the inception of SWORD, the estimated incidence of OA (in different occupational groups) and the agents responsible have remained essentially unchanged, with the exceptions of the increasing incidence of asthma associated with latex allergy in healthcare workers in the mid1990 's and a parallel decrease in asthma associated with isocyanate exposure [57].

Although few in number and limited to a handful of workplaces, cohort studies of laboratory animal workers, bakery workers and acid anhydride workers in the 1990's all found that the risk of developing OA is determined less by individual susceptibility (e.g. atopy, tobacco smoking, human-leukocyte antigen phenotype) and more by the level of exposure to its causes. In general, the higher the exposure, the greater the risk, and, by implication, lowering the level of exposure reduces the incidence of disease. It is also worth noting that factors associated with sensitisation can differ according to atopic status [46]. As a consequence, epidemiological research needs first to couple studies in which associated personal and environmental factors are well identified, then to properly assess the effectiveness of interventions designed to reduce exposure and disease incidence.

Factors associated with the disease need to be identified in specific workforces in which known occupational sensitisers are present. Use of such information has recently shown that a factor significantly associated with the development of OA to laboratory animals was not atopy per se, as for almost all high-molecular-weight allergens, but, more specifically, baseline sensitisation to domestic pets [7].

Intervention studies undertaken in workforces usually and necessarily differ from the traditional randomised controlled trials of therapeutic interventions in patients, because random allocation of individuals to an intervention in the workplace is not feasible (and almost certainly unethical) and because the intervention is not blind. Several nonexperimental designs of high internal validity can be applied. A simple non- or quasiexperimental design is the "before and after" study, such as a comparison of the prevalence of symptoms before and after the introduction of a new process to reduce airborne allergen concentration. A quasi-experimental design is one in which the investigator lacks full control over the allocation and/or timing of intervention but nonetheless conducts the study as if it were an experiment, allocating subjects to groups. Inability to allocate subjects randomly is a common situation that may best be described as a quasi-experiment.

The strength of the evidence provided by such a study can be increased by making a series of prevalence measurements at intervals before and after the introduction of the new process. Extended and consistent measurements made in several workplaces where the intervention is introduced at different times in some but not all subjects (the so-called multiple-time-series design) further strengthens the evidence. Demonstrating the effectiveness of the intervention in each workplace at different times strengthens the casual inference by replication (internal validity) and it also makes it more likely that the success of the intervention will be reproduced in other situations.

There have been few studies of the effectiveness of interventions to reduce the incidence of OA and none have approached the strict requirements of the multiple-time-series design. The closest has been a study of the changing incidence of sensitisation and asthma following interventions designed to reduce the incidence of asthma and allergy in the enzyme detergent industry [44], but even in this example there are now questions as to which intervention was decisive. In the late 1960 's the enzyme Alcalase was added in powder form to laundry detergents to increase their cleaning activity. Within 
a short time of the introduction of Alcalase, FLINDT [83] reported cases of $\mathrm{OA}$ associated with immediate skin-test responses to a solution of the enzyme and studies of workforces identified high prevalences of respiratory symptoms with skin-prick test responses to Alcalase, as reviewed previously [1]. These consistent findings stimulated a search for a means to reduce the incidence of OA in the workforce and prevent it among consumers. Atopic individuals, who had been shown to be at increased risk of becoming sensitised to Alcalase, were excluded from employment in the relevant facilities and measures were taken to reduce airborne enzymedust concentration in the workplace. This was achieved by improving engineering controls and encapsulating the enzymes used in detergent manufacture. In 1977, JUNIPER et al. [44] reported the results of a 7-yr follow-up of the workforce from the factory that had employed the original cases of FLINDT [83]. During this period atopics had been excluded from employment and the airborne enzyme concentration progressively reduced. The study population included all employees working in the factory in 1968 when enzymes were introduced into detergent manufacture and those employed during the next 7 yrs. Total dust and enzyme concentrations in the air were measured in the packing area of the factory during the period of the study. Concentrations of both were highest in 1969 and 1970, with peak concentrations of total dust exceeding $1200 \mathrm{mg} \cdot \mathrm{m}^{-3}$, subsequently falling, and rarely exceeding $400 \mathrm{mg} \cdot \mathrm{m}^{-3}$ after 1972 . The proportion of nonatopic workers who developed an immediate skin-test response to the enzyme Alcalase fell with each successive era of employment and corresponding decrease in airborne enzyme concentration as follows: 1968-1969, 41\%; 1969-1971, 29\%; 1971-1973, 11\%. In addition, the number of cases transferred out of the factory because of development of respiratory symptoms fell by: 50 from 1968-1971; and one per year from 1972-1974.

This study, although incomplete in some respects, remains one of the few to have related a fall in the attack rate of enzyme sensitisation and asthma to a measured estimate of airborne enzyme concentration. Although not fulfilling the rigorous requirements of a multiple-time-series design, it provides a series of measures of attack rates of relevant outcomes during a period of $7 \mathrm{yrs}$, with strong inference from the parallel concentration and attack rates following progressively improving interventions in the factory. The experience of this factory is paralleled by the general experience in the enzyme detergent industry in UK [84]. In addition, since the introduction of encapsulated enzymes, no cases of enzyme allergy attributable to the use of enzyme detergents have been reported among consumers. The risk does seem to persist in workers, however, as demonstrated by a recent outbreak of asthma in a modern detergent factory in northern Europe [85]. The factory had used only encapsulated enzymes (protease, cellulase and bacterial amylase) since starting production in the early 1990's, yet it experienced an outbreak of OA at least equal in magnitude to those experienced in the late 1960 's. More than 50 cases were identified in a workforce of $<350$ employees and this was attributable to the failure of engineering controls and personnel surveillance.

In the case of another sensitiser, laboratory animals, Bотнам et al. [86] reported a progressive reduction in the incidence of allergic symptoms (of eyes and nose) and asthma in employees encountering small animals in their work in a pharmaceutical research facility. The incidence of symptoms during the first year of exposure was as follows: $37 \%$ in 1980; $37 \%$ in $1981 ; 20 \%$ in $1982 ; 10 \%$ in 1983 ; and $12 \%$ in 1984 . A reduction in the incidence of symptoms was also observed after 2 and 3 yrs of exposure among the 1981 and 1982 entrants as compared with the 1980 entrants. Interestingly, although atopy was associated with an increased risk of developing symptoms in the first year, nonatopics were more likely to become symptomatic in the 2 nd and $3 \mathrm{rd}$ yrs of exposure. These reductions in disease incidence occurred concurrently with the introduction of a site code of practice for working with animals designed to decrease exposure to airborne laboratory animal allergens and with an educational programme designed to increase awareness of the hazard. Unfortunately, as the authors point out, although it seems likely, it is not definite that the decreased incidence of exposure is attributable to reduced levels of airborne animal allergens, as no measurements of aero-allergen were made during the period of the study.

As a final and valuable example, TARLO and Liss [87] demonstrated the effectiveness of a combined programme of exposure control and personnel surveillance in reducing the incidence of isocyanate-induced asthma in Ontario, Canada. Isocyanates had been responsible for $50 \%$ of cases of OA in Ontario and were targeted for control. A planned programme of exposure control in the workplace coupled with regular medical surveillance of the exposed workforce led initially to the identification of more cases, but subsequently to a reduction in disease incidence (but not for the other causes of OA in the province), with cases identified at an earlier and more remediable stage of disease.

The frequency and persistence of occupational asthma, associated as they are with severe financial and social consequences, indicate a clear need for interventions to reduce the disease's incidence. The challenge for industry, government agencies and the scientific community is to design interventions, both engineering and economic, to achieve this. The challenge for epidemiology is to design evaluative studies of sufficient strength to test the effectiveness of interventions from which the right lessons are learnt.

Acknowledgements. The authors would like to thank L. Schubert for reviewing the manuscript.

\section{References}

1. Becklake M, Malo JL, Chan-Yeung M. Epidemiological approaches in occupational asthma. In: Asthma in the workplace. Bernstein IL, Chan-Yeung M, Malo JL, Bernstein DI, eds. New York, Marcel Dekker Inc., 1999; pp. 27-65.

2. Newman-Taylor A, Venables K. Clinical and epidemiological methods in investigating occupational asthma. Clin Allergy Immunol 1984; 4: 3-17.

3. Monso E, Malo JL, Infante-Rivard C, L'Archevêque J, Magnan M, Gautrin D. Work-related symptoms in apprentices who quit an apprenticeship with exposure to highmolecular-weight agents. Eur Respir J 1998; 12: Suppl. 29, 78 s.

4. Gautrin D, Infante-Rivard C, Dao T, Magnan-Larose M, Desjardins D, Malo JL. Specific IgE-dependent sensitization, atopy and bronchial hyperresponsiveness in apprentices starting exposure to protein-derived agents. Am J Respir Crit Care Med 1997; 155: 1841-1847.

5. De Zotti RD, Bovenzi M. Prospective study of work related respiratory symptoms in trainee bakers. Occup Environ Med 2000; 57: 58-61.

6. Gautrin D, Ghezzo H, Infante-Rivard C, Malo JL. Incidence and determinants of IgE-mediated sensitization in apprentices: a prospective study. Am J Respir Crit Care Med 2000; 162: $1222-1228$.

7. Gautrin D, Infante-Rivard C, Ghezzo H, Malo JL. Incidence and host determinants of probable occupational asthma in apprentices exposed to laboratory animals. Am J Respir Crit Care Med 2001; 163: 899-904.

8. Gautrin D, Ghezzo H, Infante-Rivard C, Malo JL. Natural 
history of sensitization, symptoms and diseases in apprentices exposed to laboratory animals. Eur Respir J 2001; 17: 904-908.

9. Archambault S, Malo JL, Infante-Rivard C, Ghezzo H, Gautrin D. Incidence of sensitization, symptoms and probable occupational rhinoconjunctivitis and asthma in apprentices starting exposure to latex. $J$ Allergy Clin Immunol 2001; 107: 921-923.

10. Gautrin D, Ghezzo H, Infante-Rivard C, Malo JL. Incidence and host determinants of work-related rhinoconjunctivitis in apprentice pastry-makers. Allergy 2002; 57: 913-918.

11. Cullinan P, Cook A, Gordon S, et al. Allergen exposure, atopy and smoking as determinants of allergy to rats in a cohort of laboratory employees. Eur Respir J 1999; 13: 11391143 .

12. Cullinan P, Cook A, Nieuwenhuijsen M, et al. Allergen and dust exposure as determinants of work-related symptoms and sensitization in a cohort of flour-exposed workers; a case-control analysis. Ann Occup Hyg 2001; 45: 97-103.

13. www.asmanet.com. Date last updated: continuous.

14. www.asthme.csst.qc.ca. Date last updated: continuous.

15. Burney $\mathrm{P}$, Laitinen L, Perdrizet S, et al. Validity and repeatability of the IUATLD (1984) bronchial symptoms questionnaire: an international comparison. Eur Respir $J$ 1989; 2: 940-945.

16. Toelle B, Peat J, Salome C, Mellis C, Woolcock A. Toward a definition of asthma for epidemiology. Am Rev Respir Dis 1992; 146: 633-637.

17. Troyanov S, Malo JL, Cartier A, Gautrin D. Frequency and determinants of exaggerated bronchoconstriction during shortened methacholine challenge tests in epidemiological and clinical set-ups. Eur Respir J 2000; 16: 9-14.

18. Malo JL, Cartier A, L'Archevêque J, et al. Prevalence of occupational asthma and immunologic sensitization to psyllium among health personnel in chronic care hospitals. Am Rev Respir Dis 1990; 142: 1359-1366.

19. Gannon P, Newton D, Belcher J, Pantin C, Burge P. Development of OASYS-2: a system for the analysis of serial measurement of peak expiratory flow in workers with suspected occupational asthma. Thorax 1996; 51: 484 489.

20. Meredith S, McDonald J. Work related respiratory disease in the United Kingdom, 1989-1992: Report on the SWORD project. Occup Med 1994; 44: 183-189.

21. Sears M, Lewis S, Herbiso G, et al. Comparison of reported prevalences of recent asthma in longitudinal and crosssectional studies. Eur Respir J 1997; 10: 51-54.

22. Bernstein IL, Chan-Yeung M, Malo JL, Berstein DI. Asthma in the workplace. 2nd edn. New York, Marcel Dekker Inc., 1999.

23. Monso E, Magarolas R, Badorrey I, Radon K, Nowak D, Morera J. Occupational asthma in greenhouse flower and ornamental plant growers. Am J Respir Crit Care Med 2002; 165: 954-960.

24. Siracusa A, Kennedy S, DyBuncio A, Lin F, Marabini A, Chan-Yeung M. Prevalence and predictors of asthma in working groups in British Columbia. Am J Ind Med 1995; 28 : 411-423.

25. Johnson A, Dimich-Ward H, Manfreda J, et al. Occupational asthma in adults in six Canadian communities. Am J Respir Crit Care Med 2000; 162: 2058-2062.

26. Kogevinas M, Anto J, Soriano J, Tobias A, Burney P, Study TSGotEA. The risk of asthma attributable to occupational exposures: A population-based study in Spain. Am J Respir Crit Care Med 1996; 154: 137-143.

27. Kogevinas M, Anto J, Sunyer J, et al. Occupational asthma in Europe and other industrialised areas: a population-based study. Lancet 1999; 353: 1750-1754.

28. Arif A, Whitehead L, Delclos G, Tortolero S, Lee E. Prevalence and risk factors of work related asthma by industry among United States workers: data from the third national health and nutrition examination survey (1988-94). Occup Environ Med 2002; 59: 505-511.

29. Cartier A, Malo JL, Forest F, et al. Occupational asthma in snow crab-processing workers. J Allergy Clin Immunol 1984; 74: 261-269.

30. Bakke P, Hanoa R, Gulsvik A. Relation of occupational exposure to respiratory symptoms and asthma in a general population sample: self-reported versus interview-based exposure data. Am J Epidemiol 2001; 154: 477-483.

31. Cullinan $\mathrm{P}$, Lowson D, Nieuwenshuijsen $\mathrm{M}$, et al. Work related symptoms, sensitisation, and estimated exposure in workers not previously exposed to flour. Occup Environ Med 1994; 51: 579-583.

32. Burge P, Pantin C, Newton D, et al. Development of an expert system for the interpretation of serial peak expiratory flow measurements in the diagnosis of occupational asthma. Occup Environ Med 1999; 56: 758-764.

33. Palmer K, Crane G. Respiratory disease in workers exposed to colophony solder flux fumes: continuing health concerns. Occup Med 1997; 47: 491-496.

34. Baldwin D, Gannon P, Bright $\mathrm{P}$, et al. Interpretation of occupational peak flow records: level of agreement between expert clinicians and Oasys-2. Thorax 2002; 57: 860-864.

35. Toren K, Brisman J, Olin A, Blanc P. Asthma on the job: work-related factors in new-onset asthma and in exacerbations of pre-existing asthma. Respir Med 2000; 94: 529-535.

36. Bardy J, Malo JL, Séguin P, Ghezzo H, Desjardins J, Dolovich J, Cartier A. Occupational asthma and $\operatorname{IgE}$ sensitization in a pharmaceutical company processing psyllium. Am Rev Respir Dis 1987; 135: 1033-1038.

37. Chan-Yeung M, Malo JL. Occupational asthma. $N$ Engl J Med 1995; 333: 107-112.

38. Post W, Venables K, Ross D, Cullinan P, Heederik D, Burdorf A. Stepwise health surveillance for bronchial irritability syndrome in workers at risk of occupational respiratory disease. Occup Environ Med 1998; 55: 119-125.

39. Janson C, Anto J, Burney $\mathrm{P}$, et al. The European Community Respiratory Health Survey: what are the main results so far? Eur Repir J 2001; 18: 598-611.

40. Talini D, Benvenuti A, Carrara M, Vaghetti E, Martini LB, Paggiaro P. Diagnosis of flour-induced occupational asthma in a cross-sectional study. Respir Med 2002; 96: 236-243.

41. Burney P, Luczynska C, Chinn S, Jarvis D. The European Community Respiratory Health Survey. Eur Respir J 1994; 7: 954-960.

42. Fishwick D, Pearce N, D'Souza W, et al. Occupational asthma in New Zealanders: a population based study. Occup Environ Med 1997; 54: 301-306.

43. Blanc P, Ellbjar S, Janson C, et al. Asthma-related work disability in Sweden. Am J Respir Crit Care Med 1999; 160: 2028-2033.

44. Juniper C, How M, Goodwin B. Bacillus subtilis enzymes: a 7-year clinical, epidemiological and immunological study of an industrial allergen. J Soc Occup Med 1977; 27: 3-12.

45. Malo JL, Yeung MC. Occupational asthma. J Allergy Clin Immunol 2001; 108: 317-328.

46. Gautrin D, Ghezzo H, Infante-Rivard C, Malo JL. Host determinants for the development of allergy in apprentices exposed to laboratory animals. Eur Respir J 2002; 19: 96103 .

47. Brisman J, Järvholm B. Occurrence of self-reported asthma among Swedish bakers. Scand J Work Environ Health 1995; 21: 487-494.

48. Tarlo S, Leung K, Broder I, Silverman F, Holness D. Asthmatic subjects symptomatically worse at work: Prevalence and characterization among a general asthma clinic population. Chest 2000; 118: 1309-1314.

49. Newman-Taylor AJ. Asthma and work. Ann Occup Hyg 2002; 46: 563-574.

50. Ameille J, Parion J, Bayeux M, et al. Consequences of occupational asthma on employment and financial status: a follow-up study. Eur Respir J 1997; 10: 55-58. 
51. Vandenplas O, Cangh FB-V, Brumagne A, et al. Occupational asthma in symptomatic workers exposed to natural rubber latex: Evaluation of diagnostic procedures. $J$ Allergy Clin Immunol 2001; 107: 542-547.

52. Kopferschmitt-Kubler M, Ameille J, Popin E, et al. Occupational asthma in France: a 1-yr report of the Observatoire National de Asthmes Professionnels project. Eur Respir $J$ 2002; 19: 84-89.

53. Lagier F, Cartier A, Malo JL. Statistiques médico-légales sur l'asthme professionnel au Québec de 1986 à 1988. [Medicolegal statistics on occupational asthma in Quebec between 1986 and 1988]. Rev Mal Respir 1990; 7: 337-341.

54. Karjalainen A, Kurppa K, Virtanen S, Keskinen H, Nordman H. Incidence of occupational asthma by occupation and industry in Finland. Am J Ind Med 2000; 37: 451458.

55. Meredith S, Nordman H. Occupational asthma: measures of frequency from four countries. Thorax 1996; 51: 435-440.

56. Torén L. Self reported rate of occupational asthma in Sweden 1990-2. Occup Environ Med 1996; 53: 757-761.

57. McDonald J, Keynes H, Meredith S. Reported incidence of occupational asthma in the United Kingdom, 1989-97. Occup Environ Med 2000; 57: 823-829.

58. Gannon P, Burge P. The SHIELD scheme in the West Midlands Region, United Kingdom. Midland Thoracic Society Research Group. Br J Ind Med 1993; 50: 791-796.

59. Hnizdo E, Esterhuizen T, Rees D, Lalloo U. Occupational asthma as identified by the Surveillance of Work-related and Occupational Respiratory Diseases programme in South Africa. Clin Exp Allergy 2001; 31: 32-39.

60. Matte T, Hoffman R, Rosenman K, Stanbury M. Surveillance of occupational asthma under the SENSOR model. Chest 1990; 98: 173S-178S.

61. Jajosky RR, Harrison R, Reinisch F, et al. Surveillance of work-related asthma in selected US states using surveillance guidelines for state health departments-California, Massachusetts, Michigan and New Jersey. MMWR 1999; 48, SS3: $1-20$.

62. Contreras G, Rousseau R, Chan-Yeung M. Occupational respiratory diseases in British Columbia, Canada in 1991. Occup Env Med 1994; 51: 710-712.

63. Blanc P, Torén K. How much asthma can be attributed to occupational factors? Am J Med 1999; 107: 580-587.

64. $\mathrm{Xu} \mathrm{X}$, Christiani D. Occupational exposures and physiciandiagnosed asthma. Chest 1993; 104: 1364-1370.

65. Milton D, Solomon G, Rosiello R, Herrick R. Risk and incidence of asthma attributable to occupational exposure among HMO members. Am J Ind Med 1998; 33: 1-10.

66. Karjalainen A, Kurppa K, Martikainen R, Klaukka T, Karjalainen J. Work is related to a substantial portion of adult-onset asthma incidence in the Finnish population. Am J Resp Crit Care Med 2001; 164: 565-568.

67. Reijula K, Haahtela T, Klaukka T, Rantanen J. Incidence of occupational asthma and persistent asthma in young adults has increased in Finland. Chest 1996; 110: 58-61.

68. Karjalainen A, Kurppa K, Martikainen R, Karjalainen J, Klaukka T. Exploration of asthma risk by occupationextended analysis of an incidence study of the Finnish population. Scand J Work Environ Health 2002; 28: 49-57.

69. Wagner G, Wegman D. Occupational asthma: prevention by definition. Am J Ind Med 1998; 33: 427-429.
70. Ng T, Hong C, Goh L, Wong M, Koh K, Ling S. Risks of asthma associated with occupations in a community-based case-control study. Am J Ind Med 1994; 25: 709-718.

71. Liss G, Tarlo S. Work related asthma. Occup Environ Med 2002; 59: 503-504.

72. Jaakkola M, Nordman H, Piipari R, et al. Indoor dampness and molds and development of adult-onset asthma: a population-based incident case-control study. Environ Health Perspect 2002; 110: 543-547.

73. Thorn J, Beijer L, Rylander R. Work related symptoms among sewage workers: a nationwide survey in Sweden. Occup Environ Med 2002; 59: 562-566.

74. Renström A, Malmberg P, Larsson K, Larsson P, Sundblad B-M. Allergic sensitization is associated with increased bronchial responsiveness: a prospective study of allergy to laboratory animals. Eur Respir J 1995; 8: 1514-1519.

75. Barker R, Tongeren MV, Harris J, Gardiner K, Venables K, Newman-Taylor AJ. Risk factors for sensitisation and respiratory symptoms among workers exposed to acid anhydrides: a cohort study. Occup Environ Med 1998; 55: 684-691.

76. Sussman G, Liss G, Deal K, et al. Incidence of latex sensitization among latex glove users. J Allergy Clin Immunol 1998; 101: 171-178.

77. Meredith S, Bugler J, Clark R. Isocyanate exposure and occupational asthma: a case-referent study. Occup Environ Med 2000; 57: 830-836.

78. Houba R, Heederik D, Doekes G. Wheat sensitization and work-related symptoms in the baking industry are preventable. Am J Respir Crit Care Med 1998; 158: 1499-1503.

79. Baur X, Chen Z, Liebers V. exposure/response relationships of occupational inhalative allergens. Clin Exp Allergy 1998; 28: $537-544$.

80. Malo JL. Occupational asthma: a model for environmental asthma. Advances in allergology and clinical immunology. Godard P, Bousquet J, Michel FB, eds. Carnforth, Parthenon Publishing Group, 1992; pp. 391-400.

81. Cullinan P, Newman-Taylor A. Occupational asthma: a model for asthma acquired outside the workplace. In: Holgate ST, Boushey HA, Fabbri LM, eds. Difficult asthma. London, Martin Dunitza, 1999; pp. 113-126.

82. Nguyen B, Ghezzo H, Malo J-L, Gautrin D. Time course of onset of sensitization to common and occupational inhalants in apprentices. J Allergy Clin Immunol 2003; 111: 807-812.

83. Flindt M. Pulmonary disease due to inhalation of derivatives of Bacillus subtilis containing protelolytic enzyme. Lancet 1969; 1: 1177-1181.

84. Cathcart $\mathrm{M}$, Nicholson $\mathrm{P}$, Roberts $\mathrm{D}$, et al. Enzyme exposure, smoking and lung function in employees in the detergent industry over 20 years. Occup Med 1997; 47: 473478.

85. Cullinan P, Newman-Taylor AJ, Hole A, Jones M, Barnes F, Jolliffe G. An outbreak of asthma in a modern detergent factory. Lancet 2000; 356: 1899-1900.

86. Botham P, Davies G, Teasdale E. Allergy to laboratory animals: a prospective study of its incidence and of the influence of atopy on its development. Br J Ind Med 1987; 44: 627-632.

87. Tarlo S, Liss G. Diisocyanate-induced asthma: diagnosis, prognosis, and effects of medical surveillance measures. Appl Occup Environ Hyg 2002; 17: 902-908. 